\title{
UTILIZAÇÃO DO RESÍDUO RESULTANTE DA COMBUSTÃO DE CARVÃO MINERAL EM USINAS TERMELÉTRICAS NA PRODUÇÃO DE NOVOS MATERIAIS: UMA ANÁLISE A PARTIR DE ARTIGOS CIENTÍFICOS E DE PATENTES
}

\author{
Claudia Terezinha Kniess \\ Doutora em Ciência e Engenharia de Materiais \\ Universidade Nove de Julho \\ São Paulo - São Paulo - Brasil \\ kniesscl@yahoo.com.br \\ Priscila Rezende da Costa \\ Doutora em Administração \\ Universidade Nove de Julho \\ São Paulo - São Paulo - Brasil \\ priscilarezende@yahoo.com.br \\ Luc Quoniam \\ Doutor em Science de l'Information et de la Communication \\ Université Du Sud Toulon Var \\ Toulon - França \\ mail@quoniam.info \\ André Moraes dos Santos \\ Doutor em Administração \\ Universidade do Vale do Itajaí \\ Itajaí - Santa Catarina - Brasil \\ amsantos@univali.br
}

\section{RESUMO}

O carvão é amplamente utilizado para a produção de energia térmica. Suas cinzas, resultantes da combustão, são prejudiciais ao meio ambiente e demandam soluções para sua reutilização. Este é um problema nacional e global. Assim, o objetivo desta pesquisa foi mapear as aplicações científicas e tecnológicas, em escala global, das cinzas de carvão, na produção de materiais vítreos e cerâmicos. As bases científicas internacionais dos artigos utilizados neste estudo foram Web of Science (WOS), Scopus (SC) e Science Direct (SD). Para tratamento e análise, foram utilizadas as ferramentas Cite Space II, Carrot2 e Paper Machines (para técnica de Heat Mapping). A base tecnológica de patentes utilizada foi a Espacenet. A ferramenta de extração, tratamento e análise foi Patent2Net. Todas as ferramentas são gratuitas. Como resultado, 174 artigos e 657 documentos de patentes foram encontrados e analisados no período de 1951 a 2015. Não foram identificadas patentes brasileiras. Por outro lado, os resultados permitiram a sistematização das informações esclarecendo o estado da arte do uso de resíduos de cinzas de carvão na produção de materiais vítreos e cerâmicos, em consonância com a Política Nacional de Resíduos Sólidos e com vistas às possibilidades de inovações sustentáveis. As informações resultantes podem ser úteis para identificar patentes e tecnologias com potencial de replicação ao problema com resíduos de carvão no âmbito nacional e internacional. Como prática, o processo de mapeamento, extração e análise de informações, utilizado neste estudo, tem potencial para ser replicado em diferentes áreas de conhecimento e campos de aplicação.

Palavras-chave: Análise de patentes. Artigos científicos. Bibliometria. Cinzas de carvão. Materiais cerâmicos.

\section{USE OF WASTE FROM MINERAL COAL COMBUSTION IN THERMELETRIC MILLS IN THE PRODUCTION OF NEW MATERIALS: AN ANALYSIS FROM SCIENTIFIC AND PATENT ARTICLES}

\begin{abstract}
Coal is widely used for the production of thermal energy. Coal ashes, resulting from combustion, are harmful to the environment and demand solutions for its reuse. This is a national and global problem. Thus, the objective of this research was to map the scientific and technological applications, on a global scale, of coal ash, in the production of vitreous and ceramic materials. The international scientific data bases used in this study were Web of Science (WOS), Scopus (SC) and Science Direct (SD). For treatment and analysis of the data, we used the tools Cite Space II, Carrot2 and Paper Machines (for Heat Mapping technique), and as technological basis of patents we used Espacenet. The collection, treatment and analysis of patent information was performed with Patent2Net tool. All tools employed in this study are public and free. As a result, we founded 174 articles and 657 patent documents, in the period from 1951 to 2015. No Brazilian patents were identified. On the other hand, the results allowed the systematization of information in the state of the art on the use of coal ash wastes in the production of vitreous and ceramic materials, in line with the National Solid Waste Policy and with a view to the possibilities of sustainable innovations. The resulting information may be useful in identifying patents and technologies with potential for replication to the problem of coal residues at national and international levels. As a practice, the process of mapping, extraction and analysis. So the information from this study may be replicated in different areas of knowledge and fields of application.
\end{abstract}

Key words: Bibliometry. Ceramic materials. Coal ash. Patent analysis. Scientific articles. 
Utilização do resíduo resultante da combustão de combustão de carvão mineral em usinas termelétricas na produção de novos materiais: uma análise a partir de artigos científicos e de

patentes

\section{INTRODUÇÃO}

O crescimento da atividade industrial e de serviços, com a consequente geração de maior quantidade de resíduos, tem forçado o desenvolvimento de novas tecnologias e processos de gestão ambiental do ciclo produtivo, enfatizando o reaproveitamento e minimizando o descarte e consequente impacto ecológico (Zaman, 2015). Em consonância com preocupação ambiental, as indústrias dos diferentes setores estão buscando o desenvolvimento sustentável, por meio de: aumento de eficiência pelo uso racional de recursos naturais; reutilização ou reciclagem de resíduos; e substituição de matérias-primas alternativas menos agressivas ao meio (Carayannis e Rakhmatullin, 2014).

Um dos resíduos industriais de grande impacto ao meio ambiente é a cinza resultante da combustão de carvão mineral, oriunda, principalmente, da geração de energia térmica, sendo estas também uma das principais responsáveis pela emissão de gases que contribuem para o aquecimento global (Oberschelp et al, 2019). No Brasil, de acordo o último Balanço Energético Nacional divulgado (2015 ano base 2014), o carvão mineral foi responsável por 5,7\% da oferta interna de energia e participa de 3,2\% da matriz elétrica nacional (MME, 2015). Em relação ao cenário mundial, o carvão mineral responde por $29 \%$ da oferta interna de energia e participa de 39,2\% da oferta de energia elétrica mundial.

Sabe-se que os principais impactos ambientais produzidos durante o beneficiamento do carvão mineral decorrem da disposição de resíduos sólidos e rejeitos, em geral sob a forma de cinzas, sem valor comercial direto e depositados em áreas próximas ao local de utilização (Fungaro e Izidoro, 2006; Ríos e Williams, 2008; Singh e Siddique, 2013). Porém, pesquisas têm apontado que as cinzas resultantes da combustão do carvão mineral podem ser reaproveitadas em diversos setores, tais como a fabricação de cimento, concreto, materiais vítreos e cerâmicos, preenchimentos estruturais, estabilização de solos e síntese de zeólitos para catalizadores (Yao et al., 2015). Entretanto, mesmo com grande potencial de aplicação, somente $30 \%$ das cinzas de carvão produzidas mundialmente são reaproveitadas (Jayaranjan et al., 2014).

Assim, é importante desenvolver-se estudos que ampliem o conhecimento sobre as possibilidades de gerenciamento dos resíduos da combustão do carvão, enfatizando tecnologias e soluções que permitam redução de danos e reaproveitamento destes resíduos sólidos (Park, 2014). Infelizmente, o conhecimento sobre soluções relacionadas a problemas de impacto ambiental é, em geral, bastante disperso, fragmentado e concentrado em suas áreas de especialidade (Zaman, 2015; Freitas e Paiva, 2018).

Uma possibilidade de reutilização das cinzas de carvão encontra-se no seu uso como matériaprima para a indústria cerâmica (Kniess et al., 2010). A transformação dos rejeitos da combustão do carvão em produtos comercialmente viáveis pode representar uma solução para o impacto ecológico causado por este resíduo industrial (Glymond et al. 2018). Além da diminuição do impacto ambiental, a transformação de resíduos em produtos comerciais pode ser uma importante possibilidade de geração de emprego e renda (Freita et al., 2016).

Considerando a necessidade latente de mapeamento compreensivo das aplicações das cinzas de carvão na produção de novos materiais, no caso materiais vítreos e cerâmicos, buscou-se nas bases de patentes, uma fonte de conhecimento complementar à tradicional revisão científica (Kim e Lee, 2015). O mapeamento do conhecimento em bases de patentes é bastante útil, pois uma patente oferece a descrição necessária para a reprodução do que está sendo patenteado, além de informações sobre famílias de patentes, conhecimentos prévios, aplicação geográfica, entre outros indicadores.

Diante deste contexto, em que os artigos científicos e as patentes podem ser utilizados como fonte de informação e de conhecimento científico e técnico, objetivou-se mapear as aplicações descritoras da utilização do resíduo resultante da combustão do carvão mineral para a geração de energia, cinzas de carvão mineral, na produção de materiais vítreos e cerâmicos, em consonância com a PNRS de 2010. Para tal, utilizaram-se bases científicas internacionais de artigos, incluindo Web Of Science (WOS), Scopus (SC) e Science Direct (SD). Já a base de patentes utilizada foi a Espacenet, uma base mantida pelo European Patent Office (EPO).

A relevância da pesquisa deve-se ao mapeamento em escala internacional das aplicações descritoras da utilização de cinzas de carvão na produção de materiais vítreos e cerâmicos, visando a 
sistematização de informações esclarecedoras do "estado da arte". Acrescenta-se a isso a importância da discussão da temática "reuso de resíduos" enquanto política pública, que tem sido pauta recorrente de discussões em diferentes estratos da sociedade (instituições científicas, tecnológicas, produtivas e governamentais) como mecanismo de desenvolvimento sustentável. Particularmente no contexto acadêmico, esse estudo assumiu distinção pelo uso de fontes internacionais de informação (Web $O f$ Science, Scopus, Science Direct e Espacenet) e pela utilização de softwares de código aberto e ferramentas computacionais para extração e tratamento de dados (Cite Space II, Carrot2, Paper Machines a partir da técnica de Heat Mapping e Paten2net).

Em relação à estrutura do artigo, a seção 2 apresenta as bases teóricas e conceituais da pesquisa. Na seção 3, constam os procedimentos metodológicos. Já a seção 4, concentra a apresentação e discussão dos resultados. Na seção 5, são sintetizados os elementos descritores do estado da arte da utilização de cinzas de carvão na produção vítrea e cerâmica. Por último, na seção 6, constam as considerações finais, as limitações da pesquisa e as possibilidades de estudos futuros.

\section{REFERENCIAL TEÓRICO}

Nesta seção serão apresentados as principais bases teóricas, conceitos e referenciais utilizados nesta pesquisa. Inicia-se abordando a gestão e o reaproveitamento de resíduos e, em seguida, aprofunda-se a discussão sobre as cinzas resultantes da combustão de carvão. Por fim, apresentam-se bases que fundamentam o mapeamento de conhecimento em bases de patentes.

\section{1 Gestão e reaproveitamento de resíduos}

A atividade industrial adquiriu um caráter essencial para o consumo na sociedade contemporânea. Como consequência do processo produtivo, ocorre a emissão de resíduos poluentes (sólidos, líquidos e gasosos) com impactos danosos causados ao meio ambiente. Tendo em vista que a redução da geração de resíduos, apesar de prioritária, é tecnicamente limitada, o melhor caminho a ser seguido é o da reciclagem (Donaire, 1995; Haas, Krausmann, Wiedenhofer e Heinz, 2015).

A reciclagem de resíduos é uma oportunidade de transformação de uma fonte importante de despesas em uma fonte de faturamento ou, pelo menos, de redução das despesas de deposição. A incorporação de resíduos nos processos produtivos reduz custos e abre novas oportunidades de negócios, além de reduzir o volume de extração de matérias-primas, preservando os recursos naturais limitados (Menezes et al., 2002, Rogoff e Ross, 2016). A reciclagem é atrativa às empresas e pode se configurar como uma importante possibilidade de geração de emprego e renda, tendo impacto social mais amplo (Freita et al., 2016). O emprego de práticas sustentáveis e de gestão ambiental também pode ser um fator positivo para o consumo de produtos originais ao sinalizarem estes princípios e informações para consumidores ecologicamente conscientes (Lira , 2018). No Brasil, a consciência ecológica começa a ser despertada na medida em que, nos últimos dez anos, as leis de controle ambiental tornaram-se mais rígidas e os custos de deposição mais elevados, principalmente a partir da Política Nacional de Resíduos Sólidos (Pnrs).

\subsection{Gestão das cinzas de carvão como resíduo industrial}

O Brasil possui 5,7\% de sua matriz energética oriunda de usinas termelétricas e tende a aumentar sua participação para 7,0\% até o ano de 2030 (MME, 2014). O carvão mineral é a maior fonte de energia não-renovável no País. As maiores reservas de carvão mineral (medida) estão localizadas nos estados do Rio Grande do Sul, Santa Catarina e Paraná com 5,2 bilhões de toneladas, 1,4 bilhões de toneladas e 3,3 milhões de toneladas, respectivamente (Dnpm, 2010).

No âmbito mundial, apesar dos graves impactos sobre o meio ambiente, o carvão ainda é uma importante fonte de energia (Oberschelp et al, 2019). As principais razões para isso são: a) abundância 
Utilização do resíduo resultante da combustão de combustão de carvão mineral em usinas termelétricas na produção de novos materiais: uma análise a partir de artigos científicos e de

patentes

das reservas; b) distribuição geográfica das reservas; c) baixos custos e estabilidade nos preços, relativamente a outros combustíveis (Balanço Energético Nacional, 2011).

A combustão do carvão mineral pulverizado, geralmente para a produção de energia elétrica, se dá em altas temperaturas e resulta em resíduos sob a forma cinzas leves e pesadas. Cerca de $65 \%$ das cinzas são leves o suficiente para deixarem a caldeira arrastadas com os gases de combustão (cinzas leves). Das cinzas remanescentes, $35 \%$, caem no fundo da caldeira (cinzas pesadas) fundidas em partículas maiores (Kniess, 2005). Estima-se que cerca de 3 milhões de toneladas de cinzas de carvão são produzidas no país ao ano e este número irá aumentar devido à demanda de energia elétrica pela sociedade (Plano Nacional de Energia Elétrica 2030, 2016).

As cinzas leves são aproveitadas como adição mineral em concretos de cimento Portland (John, 2001). No entanto, a destinação das cinzas pesadas continua sendo os depósitos a céu aberto, em bacias de sedimentação, e carecem de aplicações industriais (Kniess et al., 2011). Esses depósitos são altamente agressivos ao ecossistema local, destacando-se os processos de lixiviação que levam a uma contínua contaminação dos lençóis freáticos e dos mananciais hídricos, comprometendo as fontes de abastecimento de água da região (Zocche, 2005).

As características físicas, químicas e mineralógicas das cinzas de carvão são compatíveis com várias matérias-primas utilizadas nas indústrias cerâmicas de revestimento, o que indica uma possibilidade de substituição parcial ou integral destas matérias-primas por esse resíduo para a produção de telhas cerâmicas, tijolos e blocos para várias aplicações (HAQ, Padmanabhan, Licciulli, 2015). O resíduo é fonte de compostos aluminosilicatos e é, majoritariamente, formado pelas fases cristalinas quartzo ( $\mathrm{SiO} 2)$ e mulita (3A12O3.2Si2O3), sendo estas matérias-primas não plásticas comumente utilizadas na fabricação de materiais cerâmicos (Kniess, 2005). A utilização de cinza pesada de carvão mineral no processo cerâmico apresenta diversas vantagens, tanto ambientais quanto econômicas, favorecendo a condução de processos industriais sustentáveis. Tais processos ainda não são utilizados no Brasil com a mesma intensidade que em países desenvolvidos (Skoronski et al, 2015).

$\mathrm{O}$ aumento da competitividade internacional impõe às indústrias do setor cerâmico, particularmente às de revestimentos, a necessidade inovar em seus produtos, principalmente com relação a questão ecológica (de Souza, Scur, e de Castro Hilsdorf, 2018). A busca por matérias-primas e processos de produção orientados à questão ambiental pode ser um fator diferencial, porquanto pode ser decisivo na escolha de um determinado produto pelo consumidor com consciência ecológica (Lira, 2018). Diversos trabalhos já evidenciaram o potencial de uso das cinzas pesadas como matéria-prima para a indústria cerâmica, a exemplo dos estudos de Kumar et al. (2001); Kniess et al. (2002); Santos et al., (2007); Kniess et al., (2010) e Glymond, Roberts, Russell e Cheeseman, 2018).

No Brasil, outro forte argumento para a reciclagem de cinzas de carvão é a quantidade gerada pela combustão dos carvões nacionais (sub-betuminoso), que pode chegar a mais de $50 \%$ em massa (Fungaro e Izidoro, 2006). Esta cinza pode ser utilizada como matéria-prima na produção de materiais cerâmicos, substituindo outros materiais com um custo, pelo menos, quatro vezes menor (Carvalho, Nunes, \& Vasconcelos, 2018).

Apesar da viabilidade técnica da utilização das cinzas pesadas de carvão mineral na produção de materiais cerâmicos estar comprovada (Cheeseman, Da Rocha, Sollars, Bethanis e Boccaccini, 2003; Glymond, Roberts, Russell e Cheeseman, 2018; Jayaranjan, Van Hullebusch e Annachhatre, 2014; Namkane, Naksata, Thiansem, Sooksamiti e Arqueropanyo, 2016), existe a necessidade de mapear o conhecimento distribuído em pesquisas referentes ao potencial de aproveitamento desse resíduo para a fabricação de produtos cerâmicos, bem como a produção desse material em escala industrial.

\subsection{Mapeamento do conhecimento científico e tecnológico}

O mapeamento do conhecimento científico e tecnológico em torno de um problema pode evidenciar padrões de desenvolvimento de soluções, diversificação das linhas de pesquisa, bem como o surgimento de novas áreas de aplicação. (Cecere e Martinelli, 2017). A combinação do conhecimento residente em bases científicas com o conhecimento tecnológico contido nas bases de patentes permite 
ampliar as possibilidades de análise, contribuindo para uma visão mais integrada do conhecimento no campo de estudo (Santos, Kniess, Quoniam e Maccari, 2018)

A patente pode ser considerada uma ferramenta para a disseminação da informação, podendo ser utilizada como: (a) fonte de dados para os indicadores do grau de desenvolvimento tecnológico e econômico; (b) fonte de acompanhamento da evolução tecnológica; (c) fonte de identificação detentores de tecnologias concorrentes, tendências tecnológicas e mercados potenciais (Quoniam, Kniess e Mazzieri, 2014). As patentes são importantes, uma vez que os resultados tecnológicos apresentados para realização do pedido de patenteamento raramente são replicados em outras publicações (Barroso et al., 2004).

\section{METODOLOGIA}

A pesquisa foi exploratória, com dados secundários obtidos com a prospecção em bases internacionais de artigos científicos e de patentes, com o objetivo de mapear as aplicações descritoras da utilização de cinzas de carvão na produção de materiais vítreos e cerâmicos. $\mathrm{O}$ método utilizado para coleta dos dados foi a bibliometria, ou seja, uma pesquisa de informações em banco de dados. A análise dos dados foi realizada com base em indicadores e representações gráficas.

\subsection{Bases de dados}

As bases científicas internacionais de artigos consultadas foram: Web Of Science (WOS), Science Direct (SD) e Scopus (SC). No mapeamento dos artigos no período de 2000 a 2014, utilizou-se a ferramenta Cite Space II e para a construção de clusters recorreu-se à ferramenta Carrot2 (Chen, 2006; Osiński e Weiss, 2005). Especificamente para a representação da distribuição geográfica dos artigos, aplicou-se a ferramenta Paper Machines, utilizando a técnica de Heat Mapping.

Para o mapeamento de patentes foi utilizada a base Espacenet, uma base aberta e mantida pelo European Patent Office (EPO, 2012) considerada uma das bases internacionais com maior cobertura de dados (Jürgens e Herrero-Solana, 2015). A ferramenta computacional de extração e tratamento das patentes foi o Paten2net, um software de código aberto que contribui para a otimização das informações coletadas (Ferraz et al., 2015; Quoniam, Kniess e Mazzieri, 2014).

\subsection{Método de busca}

Foram mapeados nas bases internacionais 174 artigos que continham os termos "bottom ash" e "glass" ou "ceramic" e 657 documentos de patentes, incluindo pedidos e concessões. Na investigação, foram analisados documentos de patentes depositadas por país de origem, país de depósito, depositantes, país do depositante, inventor, país do inventor, extratos (classificação da patente) e classificação das classes IPC4 e IPCR7 (IPC - Código Internacional de Patentes), caracterizando uma pesquisa de dados em bases secundárias.

\subsection{Ferramentas de extração e análise de dados}

Para a extração e tratamento de patentes, foi utilizada a ferramenta computacional Paten2net, um crawler de mineração de dados que possui as seguintes funcionalidades: (a) busca a lista de patentes num formato que permite a construção de consultas complexas, utilizando um nome de arquivo colocado como parâmetro para formar a lista de resultados; (b) utiliza o resultado obtido na busca para fornecer os dados bibliométrico (inventores, datas, país, classificação e status); e (c) possui algorritmos que possibilita criar uma rede temporal de entrada bibliográficas associadas às patentes e seus atributos, que permite a manipulação e exploração das informações colhidas de cada patente criando um gráfico completo dos dados (Quoniam, Kniess e Mazzieri, 2014).

O Patent2Net executa um conjunto de processos computacionais específicos para realização das extrações propostas. A ferramenta extrai as informações da base de patentes Espacenet, por meio de uma 
Utilização do resíduo resultante da combustão de combustão de carvão mineral em usinas termelétricas na produção de novos materiais: uma análise a partir de artigos científicos e de

patentes

conexão específica de acesso, autorizada pela base de patentes (Masiakowski \& Wang, 2013). Utilizando técnicas de data mining, a ferramenta extrai, converte e processa os textos completos das patentes obtidas com a expressão de busca. Em seguida, o software analisa as relações existentes nos dados extraídos e cria diversas visualizações em formato de redes, como, por exemplo, entre os inventores, empresas depositantes, países e classificações. Além das redes, o sistema cria tabelas e gráficos dinâmicos que podem ser consultados localmente ou disponibilizados diretamente na internet para acesso on line. Trabalhos recentes têm demonstrado a eficácia do Patent2net para realizar uma varredura sobre as patentes em diversos temas (Quoniam, Kniess e Mazzieri, 2014; Ferraz et al., 2015; Hirata et al., 2015).

\section{ANÁLISE DOS RESULTADOS}

Inicialmente buscou-se pelo termo "bottom ash" em todos os campos de pesquisa disponíveis (título, palavras-chave, abstract) nas bases de artigos científicos consideradas: Web Of Science (WOS), Scopus (SC) e Science Direct (SD). Posteriormente, foram adicionados filtros para obtenção de resultados que incluíssem os termos "ceramic" ou "glas", resultando na expressão lógica de busca ("bottom ash" and (ceramic or glass)) (Tabela 1).

\section{Tabela 1}

Artigos encontrados nas bases WOS, SC e SD de 2000 a 2014.

\begin{tabular}{lrrr}
\hline Base & $\# 1$ "bottom ash" & $\# 1$ "bottom ash" AND (ceramic OR glass) & $\# 2 / \# 1 \%$ \\
\hline Web of Science (WOS) & 211 & 174 & $8 \%$ \\
Science Direct (SD) & 892 & 71 & $7 \%$ \\
Scopus (SC) & 1774 & 130 & $7 \%$ \\
\hline
\end{tabular}

Nota: Fonte: Dados da pesquisa

Para eliminar artigos redundantes, comparou-se os resultados da busca tipo \#2 ("bottom ash" AND (ceramic OR glass)) entre as diferentes bases (Tabela 1). Verificou-se que as bases Science Direct e Scopus continham apenas 35 documentos que não eram contemplados pela base Web of Science. Destes 35 documentos, apenas 3 eram relevantes e, de fato, estavam relacionados à temática investigada, consequentemente, eles foram incluídos nas análises.

Utilizando a base WOS, elaborou-se a Figura 1 com a evolução das 2111 publicações que continham o termo "bottom ash". Observa-se um crescimento acentuado nas publicações a partir de 2006. Relacionando o termo "bottom ash" aos termos "glass or ceramic", limitou a busca por artigos relacionados diretamente à temática investigada. Nesse caso, foram encontrados 174 artigos, apenas $8 \%$ do total de artigos anteriores, no entanto, com expressivo crescimento no ritmo de publicações a partir de 2006 (Figura 2). Esse fato corrobora a percepção de que a preocupação com o reaproveitamento das cinzas de carvão é um tema ainda recente e que demanda novas e constantes pesquisas (Jayaranjan et al., 2014).

Com base nos 174 artigos que continham os termos "bottom ash" e "glass" ou "ceramic", foi realizado o mapeamento de tópicos, o que resultou em 36 diferentes clusters (Figura 3). A partir dos clusters gerados, observou-se que as pesquisas sobre cinzas de carvão foram realizadas em função de duas fontes industriais de matéria bruta: (1) os incineradores de lixo municipais e (2) usinas de geração de energia. As cinzas geradas por incineradores de lixo são um dos principais problemas ambientais de países industrializados (Puma et al., 2013). Por esse motivo, muitos estudos se concentram na possibilidade de reuso ou formas de destinação adequada para esses resíduos. Já as usinas termoelétricas também geram grandes volumes de cinzas, resultante, principalmente, da queima de carvão mineral (Bayca et al., 2008; Kniess et al., 2003). 

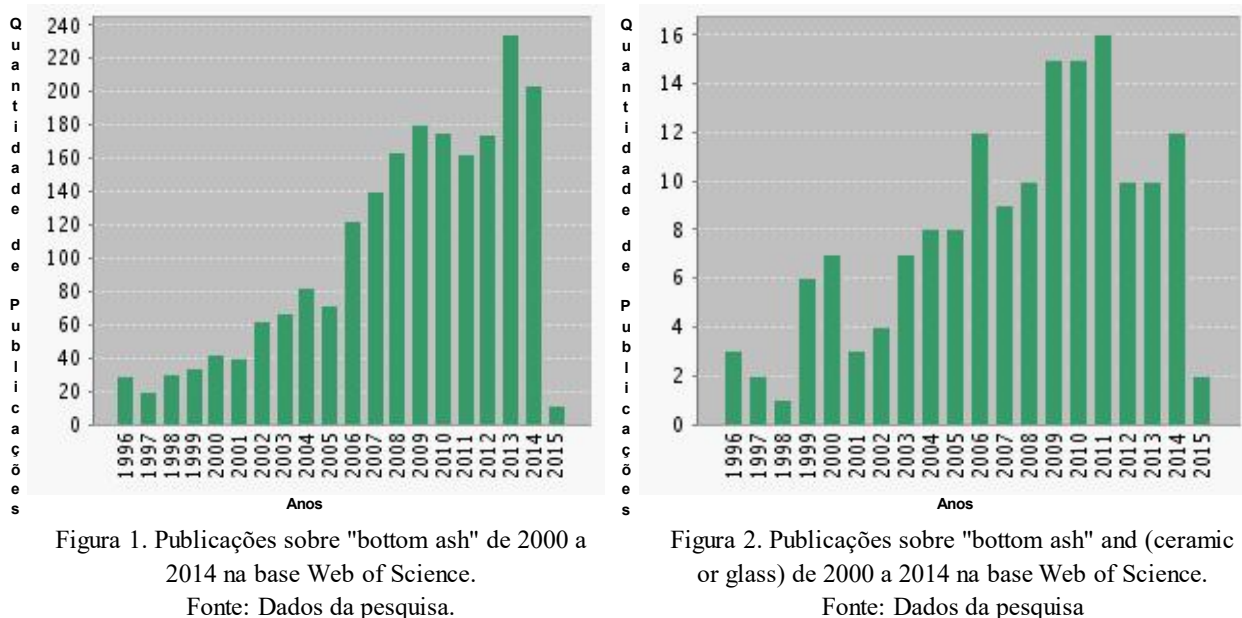

Figura 2. Publicações sobre "bottom ash" and (ceramic or glass) de 2000 a 2014 na base Web of Science. Fonte: Dados da pesquisa

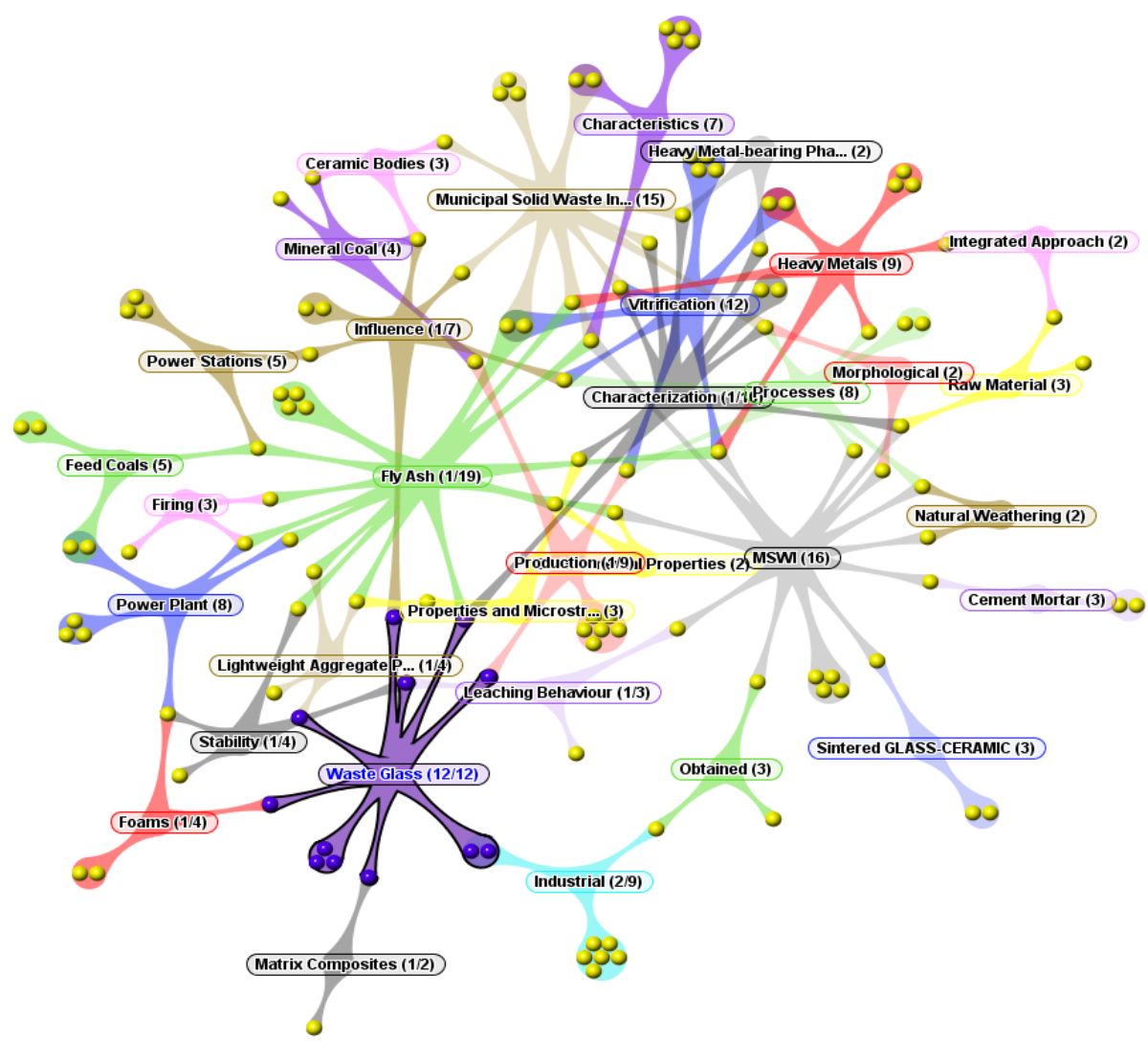

Figura 3. Clusters dos termos mapeados nos artigos selecionados (174) que tratam de cinzas de carvão e suas aplicações no setor vítreo e cerâmico.

Fonte: Dados da pesquisa

No esforço de filtrar os artigos que efetivamente versavam sobre as aplicações de "cinzas pesadas" na produção de materiais vítreos e cerâmicos, foram então selecionados apenas os artigos que possuíam a expressão "bottom ash" no título e, da amostra inicial de 174 artigos, identificaram-se 24 artigos com alta aderência à essa temática específica, vale salientar que os principais estudos surgiram no ano 2000 e foram intensificados nos anos de 2006, 2010 e 2012 (figura 4 e 5). Vale destacar que a análise em profundidade dos 24 artigos de alta aderência à temática investigada (figura 4 e 5) também possibilitou a identificação de materiais e processos inovadores no que tange a aplicação de cinzas de carvão na produção vítrea e cerâmica. Para o mapeamento dos materiais e processos inovadores projetou-se uma representação gráfica 
Utilização do resíduo resultante da combustão de combustão de carvão mineral em usinas termelétricas na produção de novos materiais: uma análise a partir de artigos científicos e de

patentes

e temporal a partir do software Paper Machines (Johnson-Roberson, 2012), conforme apresentado na Figura 4.

Especificamente sobre os materiais inovadores mapeados nos 24 artigos listados na Figura 5, observou-se que eles variam desde a simples adição de cinzas a outros materiais básicos, como vidro reciclado (Yoon e Yun, 2011), até a introdução de formulações mais específicas afim de obter vantagens no produto final ou no processo de fabricação (Kim e Kang, 2010; Kniess et al., 2007) (Figuras 4 e 5 ).

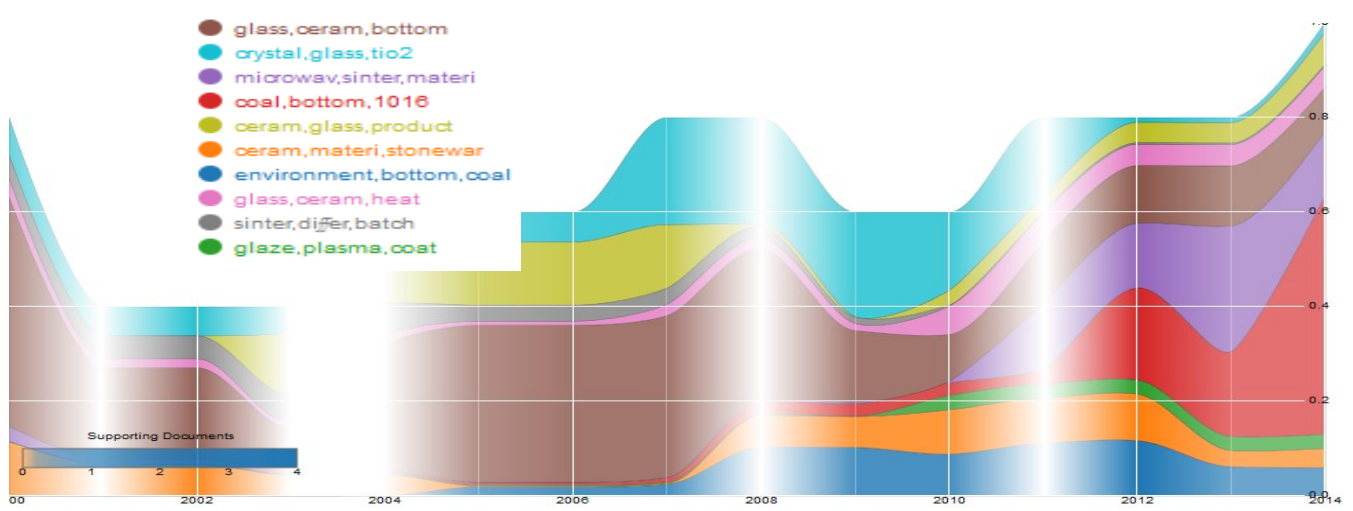

Figura 4. Representação dos materiais e processos inovadores no que tange a aplicação de cinzas de carvão na produção vítrea e cerâmica.

Fonte: Dados da pesquisa

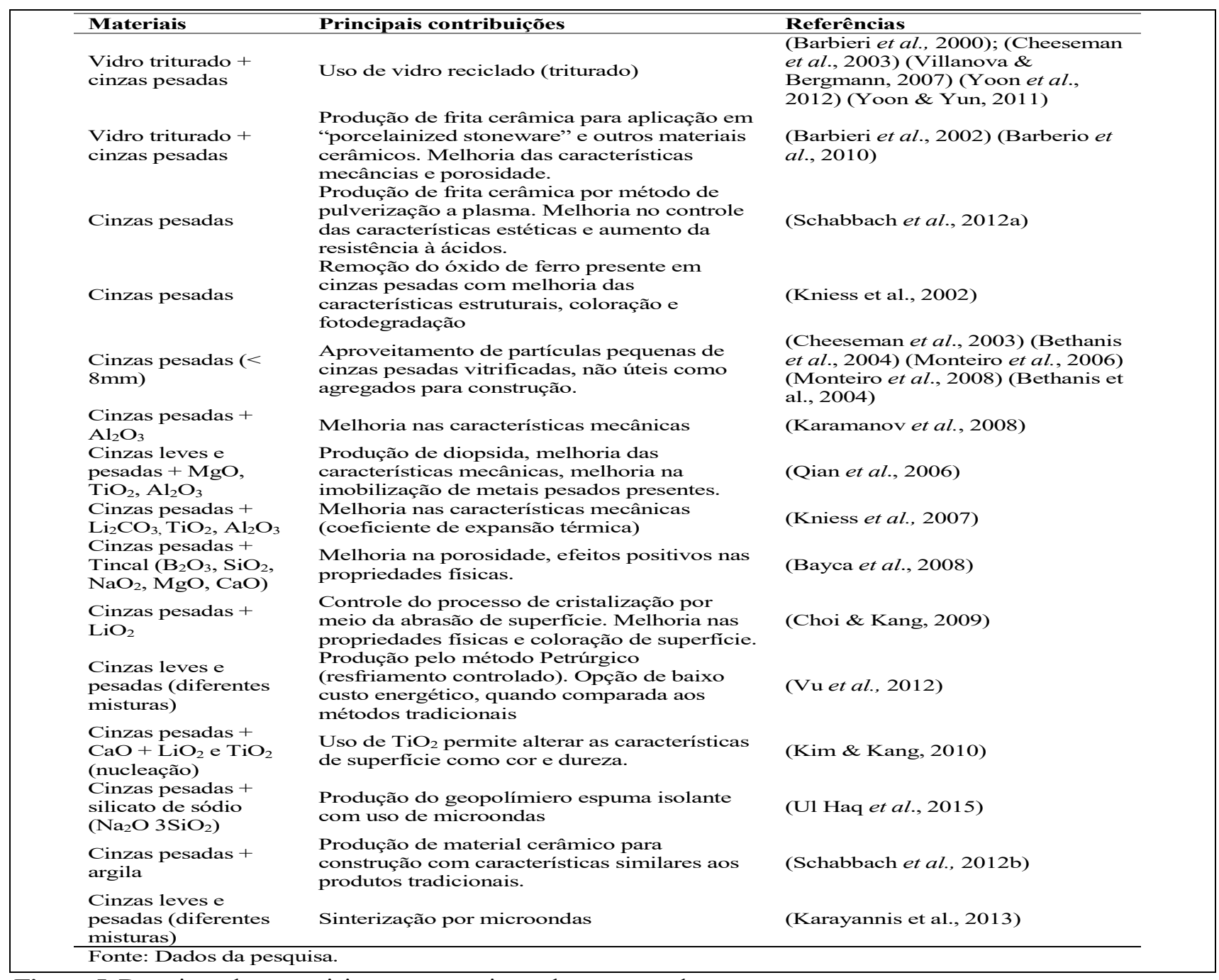

Figura 5. Descrição dos materiais e processos inovadores mapeados

Fonte: Dados da pesquisa

Revista de Gestão Social e Ambiental - RGSA, São Paulo, v. 13, n. 1, p. 76-93, jan./abr. 2019. 
Já os processos de obtenção dos produtos vitro-cerâmicos também apresentaram inovações de acordo com os 24 artigos listados na figura 6, cujos resultados centrais foram (Figuras 4 e 5):

a) "microwav, sínter, materi", relacionado ao uso de micro-ondas para o processo de fabricação de materiais cerâmicos a partir de cinzas (Ul Haq et al., 2015). A aplicação de microondas para a sinterização de cinzas em materiais cerâmicos tem sido apontada como um processo novo, econômico e eficiente (Karayannis et al., 2013).

b) "glaze, plasma, coat", se refere ao uso de spray de plasma e cinzas pesadas vitrificadas para o revestimento vítreo de materiais cerâmicos. Este processo tem sido apontado como mais efetivo do que os métodos tradicionais de revestimento "molhado", principalmente na redução de desperdício de matéria-prima quanto na produção de resíduos poluentes (Schabbach et al., 2012a).

c) Além das inovações em composições e processos, também deve-se destacar a novidade para a análise dos compostos e monitoramento dos processos de transformação, como o método Differential Thermal Analysis (DTA). Este método permite um estudo mais detalhado dos processos de nucleação e cristalização dos materiais vitro-cerâmicos (Kniess et al., 2014).

Em relação às buscas realizadas com patentes (pedidos e concessões) a partir dos termos "(ta="coal ash" or ta="coal bottom ash ${ }^{* \prime \prime)}$ and (ta=ceramic* or ta=glass*)", foram mapeados 657 documentos de patentes no período de 1951 até 2015, como significativa tendência de crescimento a partir de 2011.

Em relação aos estratos, nota-se que $84 \%$ dos documentos de patentes mapeados estão concentradas no estrato A (pedido de patente em processo de análise) (Figura 6). Dessa forma, fica evidente que as aplicações descritoras da utilização de cinzas de carvão na produção de materiais vítreos e cerâmicos foram intensificadas em anos recentes e assumem um comportamento de crescimento dado a relevância latente de preservação dos ativos ambientais e da necessidade de se efetivar mudanças sustentáveis nos meios de produção de mercadorias e no descarte de resíduos.

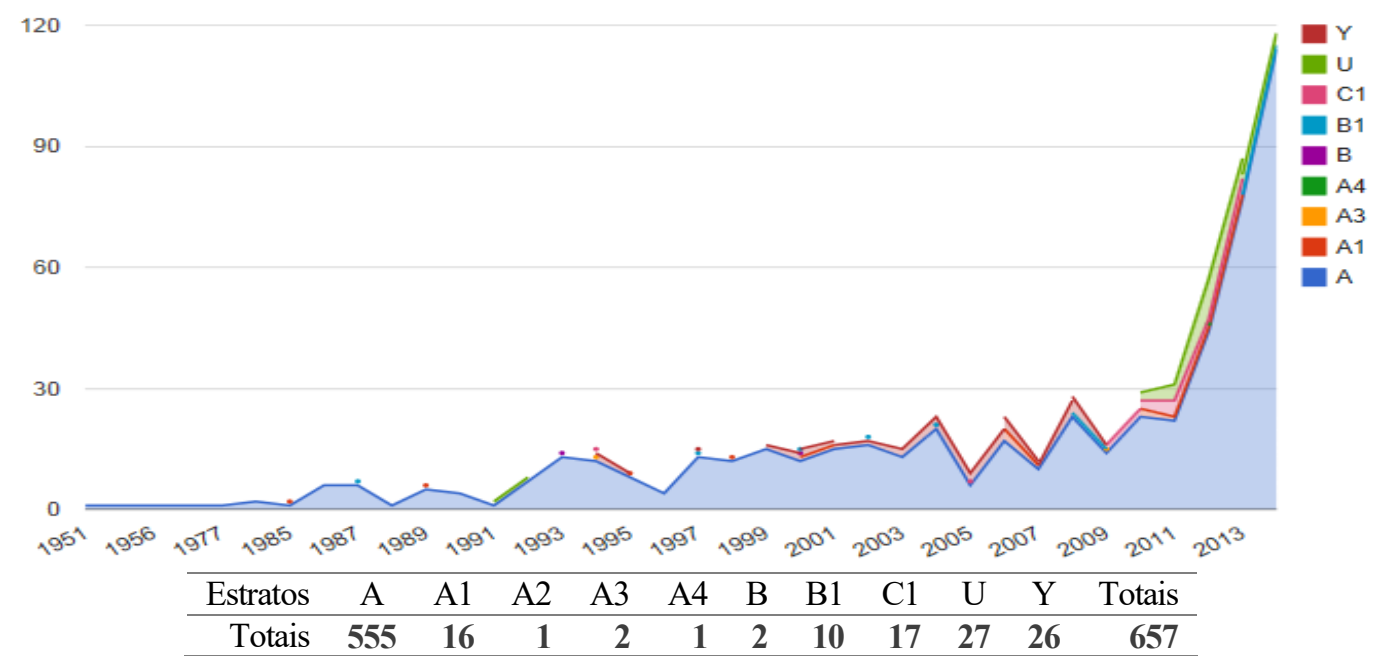

Figura 6. Distribuição dos documentos de patentes no período de 1951 a 2013

Fonte: Dados da pesquisa

Dentre os países que mais concentram documentos de patentes descritoras da utilização de cinzas de carvão na produção de materiais vítreos e cerâmicos, vale destacar a China, com 67\% (439), seguida pelo Japão, com 21\% (Tabela 2). Considerando a relação de inventores e depositantes, observa-se que a China, além de concentrar grande parte dos documentos de patentes, é também o país de origem de $66 \%$ dos inventores e de $67 \%$ dos depositantes com definição de nacionalidade mapeadas.

Avaliando de forma agregada, os países de depósito e de origem dos inventores e depositantes dos documentos de patentes mapeados, evidencia-se que a China é o país-chave no registro desses documentos no que tange à aplicação de cinzas de carvão na produção de materiais vítreos e cerâmicos, 
Utilização do resíduo resultante da combustão de combustão de carvão mineral em usinas termelétricas na produção de novos materiais: uma análise a partir de artigos científicos e de

patentes

além disso, é também o país que centraliza boa parte dos inventores e depositantes, sendo, portanto, uma referência para a pesquisa, aquisição e transferência futura de tecnologias vinculadas ao uso das cinzas de carvão na produção vítrea e cerâmica.

\section{Tabela 2}

Distribuição de patentes, considerando o país de registro, depositante e inventor

\begin{tabular}{lrr}
\hline País de registro & Inventor & Depositante \\
\hline CN & 129 & 439 \\
JP & 4 & 141 \\
Outros & 63 & 77 \\
Não identificado & 461 & - \\
\hline Total & 657 & 657 \\
\hline
\end{tabular}

Fonte: Dados de pesquisa

De forma específica, destaca-se ainda que o inventor com maior número acumulado de documentos de patentes no que tange à aplicação de cinzas de carvão na produção de materiais vítreos e cerâmicos (total de 14), nomeado de "Shchepochkina Julija Alekseevna", tem como país de origem a Rússia e manteve o registro desses documentos no referido país. Vale frisar que esses documentos foram registrados entre 2009 a 2013 e grande parte deles estão associadas à classe C04B33 que trata do processamento de produtos cerâmicos com base em materiais argilosos.

Já o depositante com maior número acumulado de documentos de patentes no que tange à aplicação de cinzas de carvão na produção de materiais vítreos e cerâmicos (total de 19), intitulado "Univ Shandong”, tem como país de origem a China e manteve o registro desses documentos no referido país. Vale frisar que esses documentos foram registrados entre 2008 a 2015, possuem estrato "A" (pedido de patente em processo de análise), grande parte deles está associada às classes C04B14 (total de 11) e C04B28 (total de 10) que se referem às composições de argamassas, concreto ou pedra artificial que contêm ligantes inorgânicos ou o produto da reação de um ácido inorgânico e um ligante orgânico.

A partir da análise agregada da relação de inventores e depositantes dos documentos de patentes mapeados, é possível inferir que é baixa a concentração de documentos por inventor e por depositante, cujo número máximo acumulado foi de 14 patentes por inventor e 19 patentes por depositante. Além disso, cabe frisar que, dos 657 documentos de patentes mapeados, se apurou 1092 inventores e 504 depositantes representados, em sua maioria, por empresas chinesas e japonesas, ou seja, uma inferência aproximada de dois inventores por documento e de um depositante para cada documento. Vale frisar, novamente, que do total de documentos de patentes mapeados (657) em apenas 196 foram mapeados inventores com definição de nacionalidade e em somente 193 foram mapeados depositantes com definição de nacionalidade.

Destaca-se ainda que o inventor com maior número acumulado de documentos de patentes, Shchepochkina Julija Alekseevna, concentra esforços patenteários no processamento de produtos cerâmicos com base em materiais argilosos, ou seja, uma temática com baixa associação ao escopo investigado na presente pesquisa que trata, especificamente, da aplicação de cinzas de carvão na produção de materiais cerâmicos. Entretanto, dados sobre composições adicionais às cinzas de carvão podem ser úteis ao desenvolvimento tecnológico de novas formulações.

No entanto, cabe pontuar que a Shandong University (depositante com maior número acumulado de documentos de patentes) configura-se como um potencial parceiro no que tange ao estabelecimento de futuros acordos internacionais de cooperação científica e tecnológica, pois boa parte dos documentos de patentes associados à referida instituição trata do uso das cinzas de carvão na produção vítrea e cerâmica.

Especificamente sobre as principais classes de patentes descritoras da utilização de cinzas de carvão na produção de materiais vítreos e cerâmicos e tendo como base o código de classificação patentearia no nível 7, foi possível inferir que as principais aplicações se encontram em (Tabela 3):

a) C04B28/00 (184 patentes): refere-se às composições de argamassas, concreto ou pedra 
artificial, que contêm ligantes inorgânicos ou o produto da reação de um ácido inorgânico e um ligante orgânico, por exemplo, cimentos de policarboxilato.

b) C04B18/00 (111 patentes): aborda-se o uso de composições químicas ou de resíduos especialmente adaptados para melhorar as propriedades ligantes em argamassas, concreto ou pedra artificial.

c) C04B38/00 (85 patentes): refere-se à obtenção de materiais porosos ou leves como argamassas, cimentos, concreto, pedras artificiais ou cerâmicas. Estão inclusos os métodos para se obter a porosidade ou a redução do peso do material final.

d) C04B14/00 (57 patentes): envolve a utilização de materiais inorgânicos especialmente adaptados para melhorar as propriedades de preenchimento, por exemplo, de pigmentos, argamassa, concreto ou pedras artificiais.

e) C04B35/00 (52 patentes): trata da obtenção de objetos cerâmicos a partir da definição de sua composição ou processo de manufatura.

f) C04B33/00 (50 patentes): refere-se aos produtos cerâmicos com base em materiais

argilosos, o processamento de materiais argilosos preparatórias para a confecção de produtos de argila e os seguintes métodos de modelagem de materiais argilosos: slip-casting e de prensagem a seco.

Tabela 3: Distribuição das principais classes descritoras das patentes mapeadas

\begin{tabular}{llllllll}
\hline \multicolumn{7}{c}{ Classificação } \\
\hline Nivel IPCR7 & C04B28 & C04B18 & C04B38 & C04B14 & C04B35 & C04B33 & Totais \\
\hline Totais & 184 & 111 & 85 & 57 & 52 & 50 & 362 \\
\hline
\end{tabular}

Nota: Fonte: Dados da pesquisa

Ainda sobre as principais classes descritoras da utilização de cinzas de carvão na produção de materiais vítreos e cerâmicos, nota-se que as aplicações vinculadas às classes C04B28, C04B18, C04B38, C04B14, C04B35 e C04B33 estão concentradas na China, totalizando 248 patentes, seguido pelo Japão com 75 (Tabela 4).

Tabela 4: Distribuição das principais classes descritoras das patentes por país de registro

\begin{tabular}{cccccccccc}
\hline & IPCR7 & \multirow{2}{*}{ C04B14 } & \multirow{2}{*}{ C04B18 } & \multirow{2}{*}{ C04B28 } & C04B33 & C04B35 & C04B38 & Totais \\
\cline { 1 - 5 } País de registro & 48 & 69 & 161 & 24 & 23 & 56 & 248 \\
CN & 4 & 29 & 18 & 9 & 23 & 24 & 75 \\
JP & 5 & 13 & 5 & 17 & 6 & 5 & 39 \\
Outros & 57 & 111 & 184 & 50 & 52 & 85 & 362 \\
\hline Totais & & &
\end{tabular}

Nota: Fonte: Dados da pesquisa.

Especificamente sobre as aplicações vinculadas à classe C04B28 (com 184 patentes, 242 inventores e 157 depositantes), nota-se uma elevada incidência de conexões com inventores e outros Ipcr7, com destaque para conexões secundárias estabelecidas com as classes C04B18, C04B14 e C04B38, conforme visualizado na Figura 7. A alta incidência de conexões deve-se, em partes, pelo alinhamento da classe em referência ao escopo investigado nessa pesquisa, pois ambos convergem para o uso de materiais inorgânicos e de resíduos (como cinzas de carvão) na produção de argamassas, concreto ou pedras artificiais (como a cerâmica) (Figura 7). 


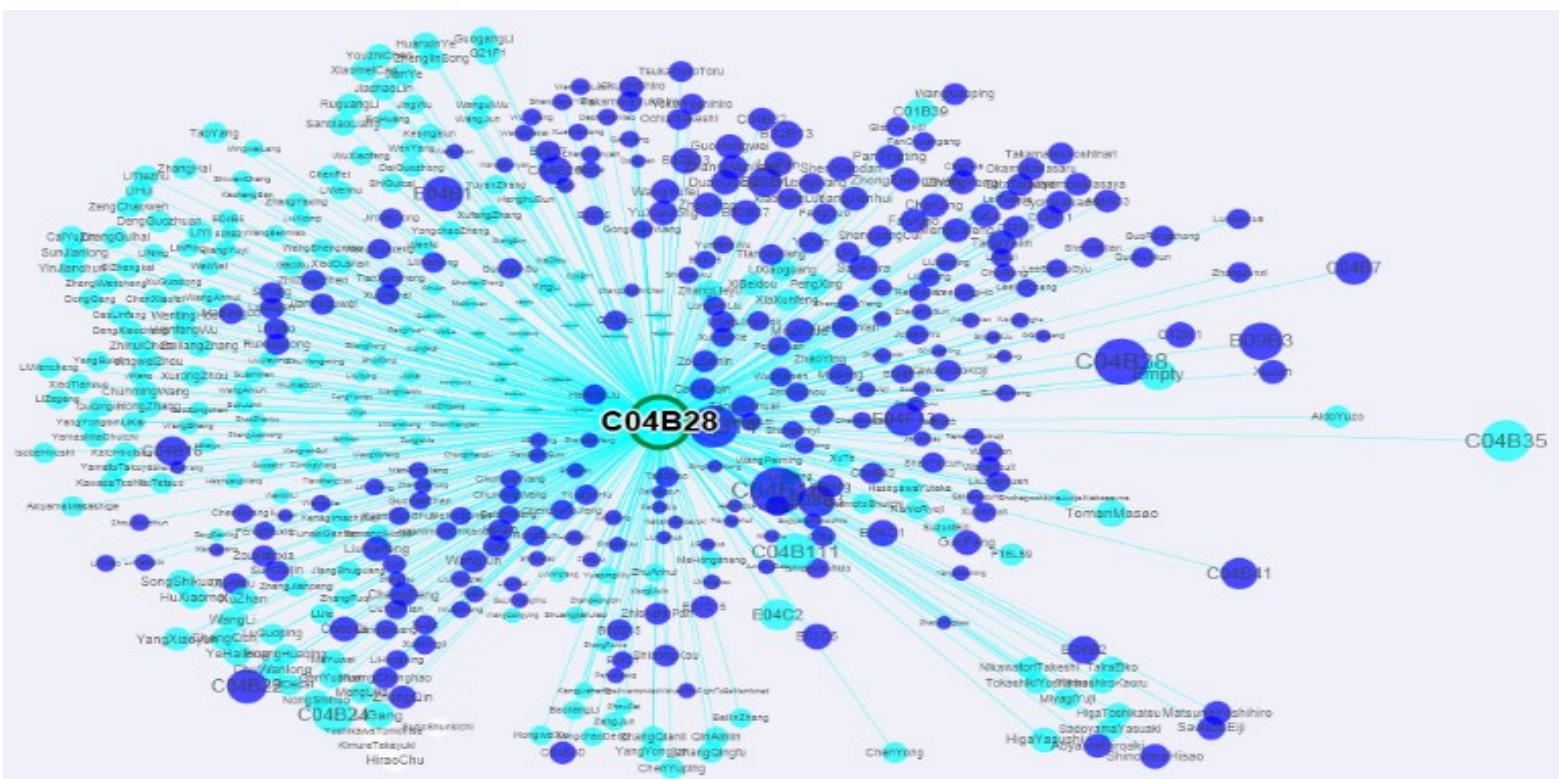

Figura 7. Representação da classe C04b28 e suas conexões com inventores e outros Ipcr7

Fonte: Dados da pesquisa

\section{DISCUSSÕES}

No que tange ao levantamento realizado junto às bases internacionais de artigos, as principais contribuições estão relacionadas ao levantamento dos artigos relevantes à aplicação de cinzas de carvão na produção vítrea e cerâmica, bem como, a identificação das principais fontes industriais de matéria bruta e a descrição dos materiais e processos inovadores. Já as buscas realizadas nas bases internacionais de patentes possibilitaram o levantamento de documentos de patentes depositados por país de origem, país de depósito, depositante, país do depositante, inventor, país do inventor, extratos (classificação da patente) e classificação das classes IPCR7 (Figura 8).

Quando se analisam os conhecimentos científico e o tecnológico mapeados neste estudo é possível visualizar as várias alternativas de soluções para o reaproveitamento das cinzas de carvão. Destaca-se que os países altamente dependentes da geração de energia a base de carvão, tais como China e Rússia, também são aqueles onde encontrou-se expressiva produção científica e tecnológica para o tratamento dos resíduos. Isto pode indicar a formação de políticas públicas efetivas de estímulo a gestão ambiental de resíduos sólidos, com a geração de soluções reais baseadas nos problemas locais. Da mesma forma, encontra-se no Japão uma grande concentração de soluções para tratamento de cinzas, visto que esta chegou a representar, no passado, $50 \%$ da matriz energética do país. Assim, percebe-se um alinhamento entre problemas locais e produção de conhecimento e soluções tecnológicas realmente aplicadas. Neste aspecto, as patentes foram importantes indicadores da transformação do conhecimento científico em tecnologias aplicadas.

No Brasil, ainda que o reuso e destinação das cinzas de carvão seja um problema importante, os dados desta pesquisa revelaram que a geração de soluções tecnológicas se mostrou inexpressiva, no que se refere a patentes, ainda que existam registros de produção científica no campo. Esta lacuna, entre o conhecimento científico e a efetiva aplicação tecnológica em bens e processos, evidencia a dificuldade na gestão ambiental de resíduos sólidos.

A riqueza e diversidade de soluções, tanto na formulação quanto no processo, para novos produtos com base nas cinzas de carvão demonstram a amplitude do problema e seu reconhecimento por diferentes áreas científicas e tecnológicas. A abundância de soluções pode indicar que a barreira para uma efetiva ação de reaproveitamento destes resíduos não está localizada na geração do conhecimento, mas sim no seu uso aplicação. No cenário de inovação, além do conhecimento, é necessário que exista esforço empreendedor, infraestrutura governamental, políticas públicas, recursos e capacidade industrial para que as ideias se transformem em produtos comercialmente viáveis, capazes de gerar crescimento econômico. 


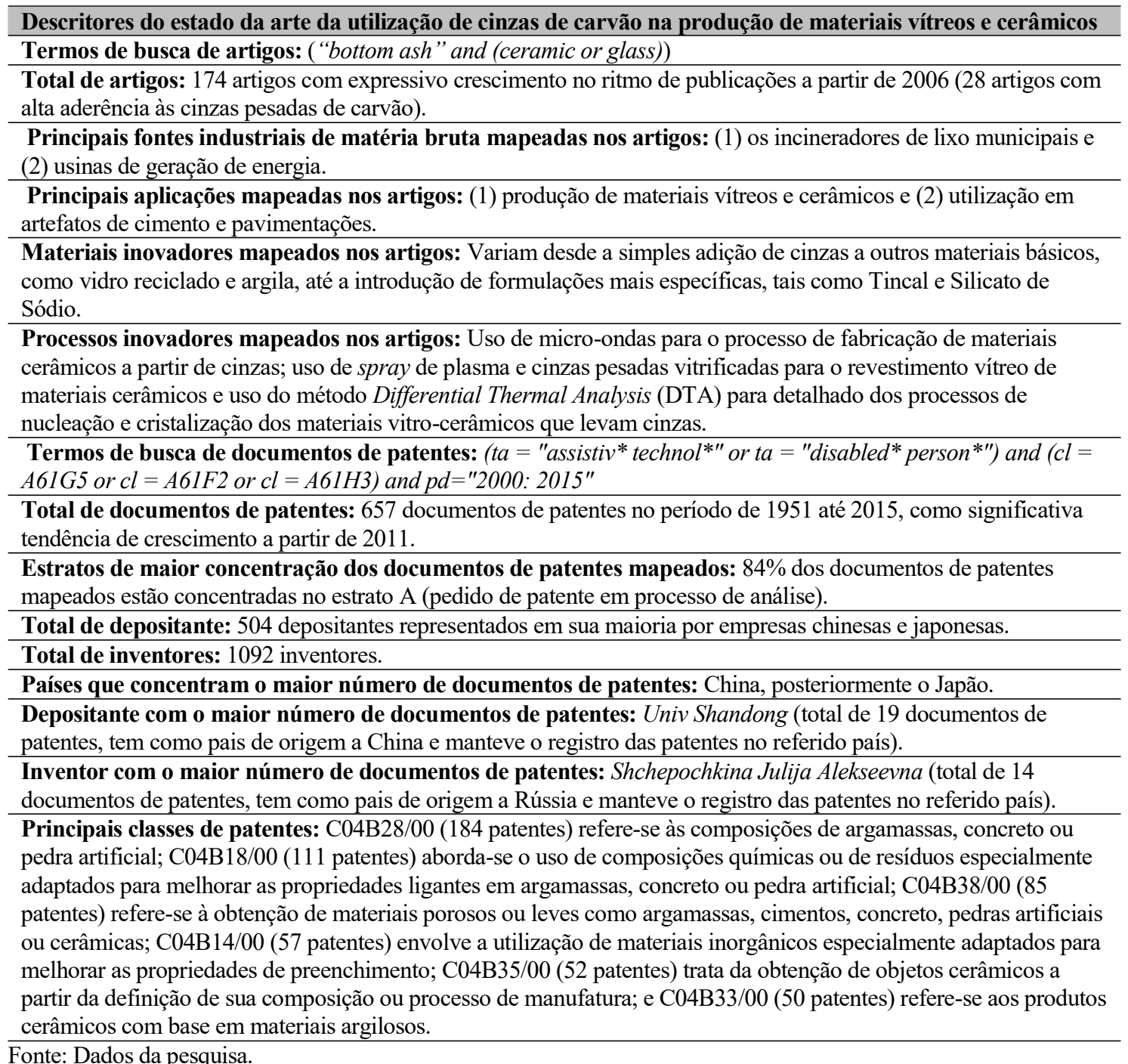

Figura 8: Descritores do estado da arte da utilização de cinzas de carvão na produção vítrea e cerâmica Fonte: Dados da pesquisa

\section{CONSIDERAÇÕES FINAIS}

As principais contribuições do estudo estão associadas à sistematização de informações esclarecedoras do "estado da arte" da utilização do resíduo resultante da combustão de carvão mineral em usinas termelétricas na produção de materiais vítreos e cerâmicos, envolvendo, especificamente, informações sobre o composto de insumos para a fabricação de materiais vitro-cerâmicos a partir de cinzas de carvão, bem como os processos e tratamento térmicos e análise das características, a toxidade e resistência a longo prazo dos produtos finais. Além dessas informações, foram também levantados sobre a temática investigada documentos de patentes depositados por país de origem, país de depósito, depositante, país do depositante, inventor, país do inventor, extratos (classificação da patente) e classificação das classes Ipcr7. Estes dados sistematizados também contribuem para a iniciativa de ciência aberta, pois estão formatados de forma a permitir sua consulta e análise on-line, utilizando apenas softwares livres e gratuitos.

Vale frisar que a combinação de novos elementos às cinzas pesadas e o aperfeiçoamento ou a inovação de processos tem permitido a obtenção de materiais com maior resistência mecânica, menor porosidade e maior controle de suas características estéticas. Como resultado, os produtos derivados do reaproveitamento de cinzas são potencialmente mais econômicos e melhores que seus similares 
Utilização do resíduo resultante da combustão de combustão de carvão mineral em usinas termelétricas na produção de novos materiais: uma análise a partir de artigos científicos e de

patentes

produzidos a partir de matérias-primas virgens (Jayaranjan et al., 2014). Segundo Barbieri (2010), para atender às dimensões da sustentabilidade, as inovações devem gerar resultados econômicos, sociais e ambientais positivos, ao mesmo tempo. Nesse contexto, encontra-se a inovação sustentável, defendida como a introdução (produção, assimilação ou exploração) de produtos, processos produtivos, métodos de gestão ou negócios, que sejam novos ou significativamente melhorados para a organização em questão, trazendo benefícios econômicos, sociais e ambientais, quando comparados com alternativas pertinentes. (Barbieri, 2010),

O estudo também produziu informações que podem contribuir para solucionar o risco potencial à saúde das cinzas de carvão, conforme demonstrado em um estudo com base nos resíduos da usina termoelétrica de Santa Catarina, Brasil (Silva e Da Boit, 2011). Embora a toxidade pulmonar das partículas de cinzas de carvão seja conhecida, o efeito das nanopartículas existentes nas cinzas ainda é desconhecido e precisa ser melhor estudado. Assim, a identificação de tecnologias e produtos que promovam o reaproveitamento das cinzas torna-se ainda mais importante e desejável.

Embora o Brasil seja incipiente no tocante ao desenvolvimento de produtos tecnológicos para o problema das cinzas de carvão, semelhante ao que acontece em nações irmãs como o México (Quintero e Rodríguez, 2015), é possível utilizar as informações deste estudo utilizada para selecionar patentes concedidas e não estendidas ao Brasil, o que permite o aproveitamento de tais tecnologias. O mapeamento do estado da arte também pode ser útil para a formulação de estratégias e políticas públicas orientadas aos problemas com resíduos de carvão no âmbito nacional.

Com relação às limitações dessa pesquisa, destaca-se que as suas conclusões estão diretamente relacionadas aos artigos e documentos de patentes mapeados. Dessa forma, as conclusões devem ser analisadas com parcimônia, uma vez que este tipo mapeamento não permite a realização de generalizações acerca das conclusões obtidas no trabalho.

Quanto às propostas de estudos futuros, destaca-se a análise de redes sociais considerando as patentes descritoras da aplicação da cinza de carvão, considerando não apenas a produção vítrea e cerâmica, como também outros processos produtivos com potencial de reuso do referido resíduo. Destacase ainda que a ferramenta computacional Patent2net, de uso livre, poderá ser utilizada para levantamento de patentes de outros resíduos, visto que estes documentos são fontes relevantes e inesgotável de informações no âmbito da tecnologia.

\section{REFERÊNCIAS}

Barbieri, J. C. et al. (2010). Inovação e sustentabilidade: novos modelos e proposições. Revista de Administração de Empresas, São Paulo, 50(2), 146-154.

Barroso, W. B. G. et al. (2004). Elaboration d'une base de données de médicaments pour faciliter la prise de décisions. Dans: VSST-2004. Toulouse, France: Dousset Bernard.

Bayca, S. U., Batar, T., Sayin, E., Solak, O. e Kahraman, B. (2008). The influence of coal bottom ash and tincal (boron mineral) additions on the physical and microstructures of ceramic bodies. Journal of Ceramic Processing Research, 9(2), 118-122.

Carayannis, E. G., Rakhmatullin, R. (2014). The quadruple/quintuple innovation helixes and smart specialisation strategies for sustainable and inclusive growth in Europe and beyond. Journal of the Knowledge Economy, 5(2), 212-239.

Cecere, G., Martinelli, A. (2017). Drivers of knowledge accumulation in electronic waste management: An analysis of publication data. Research Policy, 46(5), 925-938.

Chen, C. (2006). CiteSpace II: detecting and visualizing emerging trends and transient patterns in scientific literature. Journal of the American Society for information Science and Technology, 57(3), 359377. 
Dnpm, Departamento Nacional Da Produção Mineral (2010). Anuário Mineral Brasileiro, Brasília. Recuperado em 1 de maio de 2016, de http://www.dnpm.gov.br/ dnpm/ paginas/ anuario-mineral/ anuariomineral-brasileiro-2010

Donaire, D. A. (1995). Gestão ambiental na empresa. São Paulo: Atlas.

Ferraz, R. R., Quoniam, L. M., Reymond, D., Nigro, C. A. (2015). Exemplo de uso gratuito do OPS (Open Patent Service) para educação e informação em patentes por meio da utilização da ferramenta computacional Patent2net. In Anais do Enanpad, 39 (pp. 1-20). Belo Horizonte.

Freitas, A. R. P. de, Paiva, L. E. B. (2018). Revisão da produção científica internacional de brasileiros acerca das mudanças climáticas. Revista de Gestão Social e Ambiental, 12(3), 95-113.

Fungaro, D. A., Izidoro, J. (2006). Remediação de drenagem ácida de mina usando zeólitas sintetizadas a partir de cinzas leves de carvão. Química Nova, 29(4), 735-740.

Glymond, D., Roberts, A., Russell, M., Cheeseman, C. (2018). Production of ceramics from coal furnace bottom ash. Ceramics International, 44(3), 3009-3014.

Haas, W., Krausmann, F., Wiedenhofer, D. e Heinz, M. (2015). How circular is the global economy? An assessment of material flows, waste production, and recycling in the European Union and the World in 2005: How Circular is the Global Economy? Journal of Industrial Ecology, 19(5).

Haq E. U., Padmanabhan, S. K., Licciulli, A. (2015) Microwave synthesis of thermal insulating foams from coal derived bottom ash. Fuel Processing Technology, 130, 263 - 267.

Hirata, D., Kniess, C. T., Cortese, T. T. P., Quoniam, L. (2015). O uso de informações patentárias para a valorização de resíduos industriais: o caso do lodo de tratamento de esgoto doméstico. Revista de Ciências da Administração, 1(1), 55-71.

Jayaranjan, M. L. D., Van Hullebusch, E. D., Annachhatre, A. P. (2014). Reuse options for coal fired power plant bottom ash and fly ash. Reviews in Environmental Science and Bio/Technology, 13(4), 467486.

John, V. M. (2001). A construção, o meio ambiente e a reciclagem. Recuperado em Julho de 2012, de http://www.recycle.pcc.usp.br

Johnson-Roberson, C. (2012). Paper Machines | metaLAB (at) Harvard. Recuperado em Fevereiro de 2015, de http://metalab.harvard.edu/2012/07/paper-machines/

Jürgens, B., Herrero-Solana, V. (2015). Espacenet, patentscope and depatisnet: a comparison approach. World Patent Information, 42, 4-12.

Karayannis, V. G., Moutsatsou, A. K., Katsika, E. L. (2013). Synthesis of microwave-sintered ceramics from lignite fly and bottom ashes. Journal of Ceramic Processing Research, 14(1), 45-50.

Kim, J., Lee, S. (2015). Patent databases for innovation studies: a comparative analysis of Uspto, Epo, Jpo and Kipo. Technological Forecasting and Social Change, 92, 332-345.

Kim, W., Kang, S. (2010). Influence of Tio 2 additions on the crystallisation kinetics of a Coal bottom ash-lio 2 glass system. Journal of Ceramic Processing Research, 11(5), 557-560.

Kniess, C. T. (2005). Desenvolvimento e caracterização de materiais cerâmicos com adição de cinzas pesadas de carvão mineral (Tese de Doutorado). Universidade Federal de Santa Catarina, Santa Catarina.

Kniess, C. T. et al. (2003). Influence of coal bottom ash addition on the mechanical and physicals properties of the ceramic materials. In Anais: Fourth International Latin-American Conference On Power Technology. Guarujá. 
Utilização do resíduo resultante da combustão de combustão de carvão mineral em usinas termelétricas na produção de novos materiais: uma análise a partir de artigos científicos e de

Kniess, C. T., Borgonovo, L., Franjdlich, E. U., Martins, G., Prates, P. B., Riella, H. (2010). Influência da adição de cinzas pesadas de carvão mineral como matéria-prima na fabricação de artefatos de cimento. In Anais: Congresso Brasileiro de Cerâmica, 54. Foz do Iguaçu.

Kniess, C. T., De Borba, C. D. G., Neves, E., Kuhnen, N. C., Riella, H. G. (2002). Obtaining and characterizing $\mathrm{Li} 2 \mathrm{O}-\mathrm{A} 12 \mathrm{O} 3-\mathrm{SiO} 2$ glass-ceramics using coal bottom ash as raw material. Interceram, 51(2), 140-143.

Kniess, C. T., De Lima, J. C., Prates, P. B., Kuhnen, N. C., Riella, H. G. (2007). Dilithium dialuminium trisilicate phase obtained using coal bottom ash. Journal of Non-Crystalline Solids, 353(52), 4819-4822.

Kniess, C. T., Kuhnen, N. C., Riella, H. G., Neves, E., Borba, C. D. G. D. (2002). Study of iron oxide quantity on bottom ashes from mineral coal to glass ceramic production. Química Nova, 25(6A), 926-930.

Kniess, C. T., Martins, G. J. M., Prates, P. B., Riella, H. G., Matsinhe, J. V., Junior, J. C. G. (2014). Study of heat treatment parameters in obtaining glassceramic materials with the addition of industrial wastes. In Materials Science Forum (805).

Kniess, C. T., Prates, P. B., Martins, G., Bernardin, A., Riella, H., Bys, M. (2011). Obtenção e caracterização de produtos cerâmicos com a adição de cinzas pesadas de carvão mineral provenientes de usinas termelétricas. In Anais: Congresso Brasileiro de Cerâmica, 55. Porto De Galinhas.

Kumar, S., Singh, K. K., Ramachandrarao, P. (2001). Effects of fly ash additions on the mechanical and other properties of porcelainised stoneware tiles. Journal of materials science, 36(24), 5917-5922.

Lira, F. T. de. (2018). Fatores que influenciam a valorização de produtos ecológicos por consumidores ecologicamente conscientes. Revista de Gestão Social e Ambiental, 12(2), 90-107.

Masiakowski, P., Wang, S. (2013). Integration of software tools in patent analysis. World Patent Information, 35(2), 97-104.

Menezes, R. R., Neves, G. D. A., \& Ferreira, H. C. (2002). O estado da arte sobre o uso de resíduos como matérias-primas cerâmicas alternativas. Rev. Bras. de Eng. Agríc. e Ambiental, 6(2), 303-313.

MME (2014). Ministério de Minas de Energia. Empresa de Pesquisa Energética - EPE. Resenha Energética Brasileira. Resultados de 2014. Recuperado em 1 de maio de 2016, de http://www.mme.gov.br/web/guest/publicacoes-e-indicadores

MME (2015). Ministério de Minas de Energia. Empresa de Pesquisa Energética - EPE. Balanço Energético Nacional - BEN 2015 - Ano base 2014. Recuperado em 1 de maio de 2016, de: https://ben.epe.gov.br/

Oberschelp, C., Pfister, S., Raptis, C. E., Hellweg, S. (2019). Global emission hotspots of coal power generation. Nature Sustainability, 2(2), 113-121.

Osiński, S., Weiss, D. (2005). Carrot2: Design of a flexible and efficient web information retrieval framework. In Advances in Web Intelligence, 439-444. Springer Berlin Heidelberg.

Park, J. Y. (2014). The evolution of waste into a resource: Examining innovation in technologies reusing coal combustion by-products using patent data. Research Policy, 43(10), 1816-1826.

Plano Nacional de Energia Elétrica de 2030. Recuperado em Julho de 2011, de http:// www.epe.gov.br

Puma, S., Marchese, F., Dominijanni, A., \& Manassero, M. (2013). Reuse of MSWI bottom ash mixed with natural sodium bentonite as landfill cover material. Waste Management \& Research, 31(6), 577-584.

Quintero, G. M., Rodríguez, N. I. M. (2015). Los miembros del sistema nacional de investigadores mexicano: Un acercamiento desde la producción de patentes 2003-2012. Interciencia: Revista de ciencia y tecnología de América, 40(12), 840-846. 
Quoniam, L., Kniess, C. T., Mazzieri, M. R. (2014). A patente como objeto de pesquisa em Ciências da Informação e Comunicação. Encontros Bibli: revista eletrônica de biblioteconomia e ciência da informação, 19(39), 243-268.

Ríos, C. A., Williams, C. D. (2008). Synthesis of zeolitic materials from natural clinker: a new alternative for recycling coal combustion by-products. Fuel, 87(12), 2482-2492.

Rogoff, M. J., Ross, D. E. (2016). The future of recycling in the United States. Waste Management e Research, 34(3), 181-183.

Santos, F. I. G., Rocha, J. C., Cheriaf, M. (2007). Influência da cinza pesada empregada em substituição ao agregado natural nos mecanismos de transferência de umidade em argamassas. Revista Matéria, 12(2), 253-268.

Santos, A. M., Kniess, C. T., Quoniam, L., Maccari, E. A. (2018). Ferramentas e Bases de Dados open science para pesquisa em inovação. Revista de Negócios, 22(1), 61-73.

Schabbach, L. M., Andreola, F., Barbieri, L., Lancellotti, I., Karamanova, E., Ranguelov, B., \& Karamanov, A. (2012b). Post-treated incinerator bottom ash as alternative raw material for ceramic manufacturing. Journal of the European Ceramic Society, 32(11), 2843-2852.

Schabbach, L. M., Bolelli, G., Andreola, F., Lancellotti, I., Barbieri, L. (2012a). Valorization of Mswi bottom ash through ceramic glazing process: a new technology. Journal of Cleaner Production, 23(1), 147-157.

Silva, L. F., Da Boit, K. M. (2011). Nanominerals and nanoparticles in feed coal and bottom ash: implications for human health effects. Env. monitoring and assessment, 174(1-4), 187-197.

Singh, M., Siddique, R. (2013). Effect of coal bottom ash as partial replacement of sand on properties of concrete. Resources, Conservation and Recycling, 72, 20-32.

Skoronski, E., Souza, D. H., Santos, S., Cesino, J. C., Ghislandi, M. G (2015). Avaliação das propriedades físicas de revestimentos cerâmicos produzidos com resíduo da indústria cerâmica (cinza pesada de carvão mineral). Revista Matéria. Artigo 11592, 239 - 244.

U1 Haq, E., Padmanabhan, S. K., Licciulli, A. (2015). Microwave synthesis of thermal insulating foams from coal derived bottom ash. Fuel Processing Technology, 130, 263-267.

Yao, Z. T., Ji, X. S., Sarker, P. K., Tang, J. H., Ge, L. Q., Xia, M. S., Xi, Y. Q. (2015). A comprehensive review on the applications of coal fly ash. Earth-Science Reviews, 141, 105-121.

Yoon, S. D., Yun, Y. H. (2011). Preparation of glass ceramics from sludge bottom ash and waste glass. Journal of Ceramic Processing Research, 12(4), 361-364.

Yoon, S. D., Lee, J. U., Yun, Y. H., Yang, H. S. (2012). Chemical durability of wollastonite glassceramics derived from waste glass and sludge bottom ash. Journal of Ceramic Processing Research, 13(1), 52-55.

Zaman, A. U. (2015). A comprehensive review of the development of zero waste management: lessons learned and guidelines. Journal of Cleaner Production, 91, 12-25.

Zocche, J. J. (2005). Metais pesados (Fe, Mn, Zn) no solo construído e na vegetação das antigas bacias de decantação do lavador de Capivari, Capivari de Baixo, SC. In Anais do Simpósio Nacional e Congresso Latino-Americano de Recuperação de Áreas Degradadas. Curitiba.

\section{AGRADECIMENTOS}

Revista de Gestão Social e Ambiental - RGSA, São Paulo, v. 13, n. 1, p. 76-93, jan./abr. 2019. 
Utilização do resíduo resultante da combustão de combustão de carvão mineral em usinas termelétricas na produção de novos materiais: uma análise a partir de artigos científicos e de patentes

Os autores agradecem a ENGIE Energia (Projeto PD-0403-0036-2013) e o Conselho Nacional de Desenvolvimento Científico e Tecnológico - CNPq (Processo 311357/2016-4) pelo apoio ao desenvolvimento das pesquisas.

Este trabalho recebeu o apoio financeiro da ENGIE Energia para a sua realização

Data da submissão: 17/08/2018

Data de aceite: $12 / 12 / 2018$

Revista de Gestão Social e Ambiental - RGSA, São Paulo, v. 13, n. 1, p. 76-93, jan./abr. 2019. 